\title{
Partially Overlapped Reduction Kinetics of Low-Grade Pyrolusite by Mixture of Cellulose and Lignin
}

\author{
Yun-Fei Long ${ }^{1 \mathrm{a}}$, Xiao-Yan Lv ${ }^{2 b}$, Jing Su ${ }^{1 \mathrm{c}}$, Yan-Xuan Wen ${ }^{1 \mathrm{~d}}$ \\ ${ }^{1}$ School of Chemistry and Chemical Engineering, Guangxi University, Nanning 530004, China; \\ ${ }^{2}$ The new rural development research institute, Guangxi University, Nanning 530004, China \\ aemail: \\ longyf@gxu.edu.cn, bemail:Ivxiaoyan666@163.com, 'email:sujing928@126.com, demail:Iwenyanx \\ uan@vip.163.com,
}

Keywords: Pyrolusite; Reduction; Biomass; Kinetics

\begin{abstract}
TG/DTG was applied to study the overall kinetics for the reduction of pyrolusite by the mixture of cellulose and lignin, two major components of biomass. The respective reduction processes can be described by a new empirical equation based on the JMA equation, and the apparent activation energy is $38.66 \mathrm{~kJ} \cdot \mathrm{mol}^{-1}$ and $38.91 \mathrm{~kJ} \cdot \mathrm{mol}^{-1}$ for the reduction of pyrolusite by cellulose and lignin, respectively. Overall reduction processes of pyrolusite by the mixture of cellulose and lignin are the partial overlapped reduction processes of pyrolusite by cellulose and lignin. This overall reduction processes can be simulated by the summation of the respective kinetics by considering their mass-loss fractions.
\end{abstract}

\section{Introduction}

Manganese is widely used in many fields, such as steel production, preparation of dietary additives, fertilizers, cells and fine chemicals. ${ }^{[1]}$ To meet the ever increasing demand for manganese in company with gradual depletion of high grade manganese ore, many efforts have been made to recover manganese from low-grade pyrolusite. $\mathrm{MnO}_{2}$ in pyrolusite is stable in both acid and alkaline oxidizing conditions, so the extraction of manganese from pyrolusite must be carried out under reducing conditions. Generally, there are two major technical routes to reduce pyrolusite: one is hydrometallurgical reduction, and the other is pyrometallurgical reduction. In hydrometallurgical reduction, many kinds of reducing agents $\left(\mathrm{SO}_{2}\right.$, molasses, glucose, $\mathrm{H}_{2} \mathrm{O}_{2}, \mathrm{FeSO}_{4}$, etc.) were used to reduce the manganese dioxide of the ores in acid medium. ${ }^{[1-2]}$ However, hydrometallurgical reduction method was not widely applied in commercial practice because of its complicated purification process and serious water pollution. ${ }^{[2]}$ Pyrometallurgical reduction method with coal as reducing agent was a conventional technology of treating low-grade pyrolusite ${ }^{[1,3]}$, but this method produces a great deal of pollutants, including smoke dust, oxysulfides, nitrogen oxides, and so on. ${ }^{[1,4]}$ Moreover, it requires over $900{ }^{\circ} \mathrm{C}$ as reaction temperature, which is so high that most of the reactors can't bear. ${ }^{[1,5-7]}$ Thus, it has practical significance to develop a clean, energy-saving and environment-friendly technical route to reduce the low-grade pyrolusite.

Recently, the biomass wastes, such as sawdust, straw, cornstalk, bagasse and bagasse pith, have been investigated as a possible reducing agent to overcome such problems. ${ }^{[8-14]}$ The results showed that biomass can reduce manganese oxide of the ore at temperatures below $600^{\circ} \mathrm{C}$ with a degree of reduction more than $95 \%$. For example, Cheng et al ${ }^{[8]}$ reported that low-grade manganese dioxide ores can be totally reduced by biomass cornstalk at $500^{\circ} \mathrm{C}$. Yang et al ${ }^{[11]}$ and Long et al ${ }^{[9]}$ found that low-grade pyrolusite can be reduced completely by bagasse at $450{ }^{\circ} \mathrm{C}$. Zhou et al ${ }^{[14]}$ reported that pyrolusite can be reduced by bagasse pith at $350{ }^{\circ} \mathrm{C}$. Moreover, biomass reduction is a zero emission processes, because the amount of $\mathrm{CO}_{2}$ given out during the reduction process is equal to that absorbed during biomass growth. [15] Hence, biomass can be considered as an environment-friend, energy-saving and low-cost reducing agent for roasting reduction of manganese dioxide ores.

Meanwhile, a comprehensible understanding of the thermal reduction process and kinetics of the 
reduction reactions is needed for an efficient design of biomass reduction of pyrolusite. FT-IR and Py-GC-MS results on the thermal reduction process indicate that the reduction of pyrolusite is related to the pyrolysis of biomass. ${ }^{[14,16]}$ Based on the hypothesis of first-order reaction, Coats-Redfern method ${ }^{[17]}$ was used to determine the activation energy of the non-isothermal reduction of manganese oxide ore by biomass, such as straw, sawdust, wheat stalk and bamboo, and some valuable conclusions and insights have been obtained. ${ }^{[18-20]}$ However, there are very large varieties of biomass, meaning that it is impossible to investigate kinetics for each biomass. Therefore, it is necessary to look for a general kinetic equation to describe the reduction of pyrolusite by different kinds of biomass.

Although biomass has many types, they all contain three major components -cellulose, hemicelluloses and lignin. ${ }^{[21-22]}$ Each component of biomass has different molecular structure and nature so that it has different characteristics of the pyrolysis processes and generates different kinds of gas products, which results different reduction behaviors of pyrolusite. ${ }^{\text {[23-27] }}$ It is suggested that the superposition of the reduction behavior of three major components. So the elucidation of the reduction behavior of individual components and their mixtures is essential to a better understanding of the detail reduction mechanism and get the general kinetic equation for the reduction of pyrolusite by different types of biomass. However, the research results concerning the individual and the mixture of biomass components during the reduction of pyrolusite are limited.

In this work, TG/DTG was used to investigate the overall kinetics for the reduction of pyrolusite by the mixture of cellulose and lignin, two major components of biomass. A new empirical model function based on JMA equation was used to describe the respective kinetic behaviors of cellulose or lignin reduction of pyrolusite. On the assumption that the main components in biomass underwent individual thermo-reduction, a model on the basis of the summation of the respective kinetics was developed to simulate the overall reduction kinetics of pyrolusite by the mixture of cellulose and lignin. The information thus obtained should be necessary for better understanding of biomass reduction of pyrolusite and provide valuable assistance in the development of general kinetic equation.

\section{Materials and methods}

Pyrolusite, collected from Guangxi, China, contains 22.01 wt.\% Mn, 11.16wt.\% Fe, 27.62 wt.\% $\mathrm{SiO}_{2}$, 10.93wt.\% $\mathrm{Al}_{2} \mathrm{O}_{3}, 0.09$ wt.\% CaO, 0.12 wt.\% MgO, 0.020 wt.\% S and 0.181wt.\% P. The ore samples were crushed to $0.147 \mathrm{~mm}$ (-100 meshes). Cellulose was purchased from Beijing Chemical Reagent Company. Lignin was obtained from Sigma-Aldrich Corporation, USA. The cellulose and lignin were not further treated before mixing and testing. Table1 gives composition of the mixture of cellulose and lignin, where $x_{1}$ and $x_{2}$ are the mass ratio for cellulose and lignin, respectively. Pyrolusite was mixed with cellulose, lignin or their mixtures, respectively. Based on the reported results ${ }^{[11]}$, the mass ration of pyrolusite to cellulose, lignin or their mixtures was 10:1. The reduction of pyrolusite by cellulose, lignin and their mixture were named CP, LP, CL2, CL4, CL6, CL7 and CL8, respectively.

Table1 Composition of the mixture of cellulose and lignin

\begin{tabular}{lllllll}
\hline & CL2 & CL3 & CL4 & CL6 & CL7 & CL8 \\
\hline Cellulose $\left(x_{1}\right)$ & 0.20 & 0.30 & 0.40 & 0.60 & 0.70 & 0.80 \\
Lignin $\left(x_{2}\right)$ & 0.80 & 0.70 & 0.60 & 0.40 & 0.30 & 0.20 \\
\hline
\end{tabular}

Thermo-gravimetric analyzer (Q50TGA, TA) was applied to investigate the weight loss of the reduction of pyrolusite by cellulose, lignin and their mixture. In the TGA experiments, the sample was heated from room temperature to $800{ }^{\circ} \mathrm{C}$ at $20^{\circ} \mathrm{C} \cdot \mathrm{min}^{-1}$ in $\mathrm{N}_{2}$ atmosphere. The flow rate of nitrogen was $40 \mathrm{ml} \cdot \mathrm{min}^{-1}$ to maintain an inert atmosphere for the decomposition. The weight of each sample was set at about $20 \mathrm{mg}$. 


\section{Results and discussion}

TG/DTG experiments were carried out to measure the weight change during the reduction of pyrolusite by cellulose, lignin or their mixture under nitrogen at $20^{\circ} \mathrm{C} / \mathrm{min}$ heating rate. The weight loss behaviors of the reduction of pyrolusite by cellulose and lignin are shown in Fig. 1(a) and (b), respectively. The weight loss behaviors of the reduction processes are also subdivided into three stages. The first stage (below $200{ }^{\circ} \mathrm{C}$ ) was a loss in weight upon drying the sample, and mainly moisture was released at this stage. The second stage contributes to the main weight loss. The temperature range of the main weight loss stages are $250 \sim 410{ }^{\circ} \mathrm{C}$ and $190 \sim 410{ }^{\circ} \mathrm{C}$ for CP and LP, respectively. The maximum values of the DTG curve (weight loss rate) for CP and HP are at about $357^{\circ} \mathrm{C}$ and $340{ }^{\circ} \mathrm{C}$, respectively. The last stage was high temperature charring of the residue and the weight loss was much smaller.
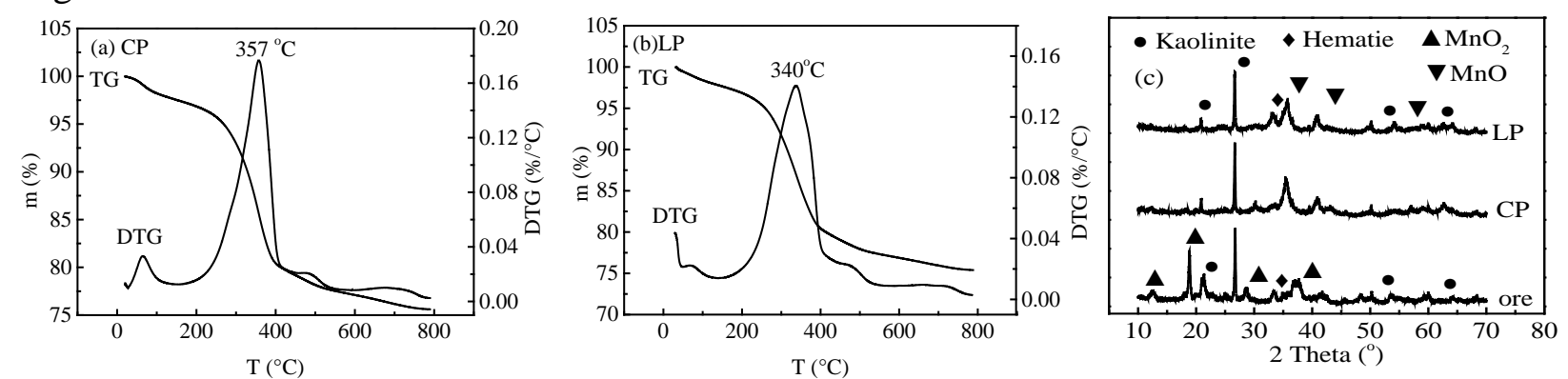

Fig. 1 TG-DTG curves and XRD for the reduction of pyrolusite by cellulose and lignin

XRD was used to identify the mineralogical composition of ore samples before roast and after roast at $400^{\circ} \mathrm{C}$ for $30 \mathrm{~min}$. The corresponding XRD patterns are shown in Fig.1(c). The original ore comprises of pyrolusite $\left(\mathrm{MnO}_{2}\right)$, hematite $\left(\mathrm{Fe}_{2} \mathrm{O}_{3}\right)$, silicon oxide $\left(\mathrm{SiO}_{2}\right)$, while its roasted products are mainly manganese oxide $(\mathrm{MnO})$, hematite and kaolinite. Hence, reduction processes of pyrolusite by cellulose and lignin are completed in the second stage of TG/DTG curves in Fig. 1(a) and (b).

Fig.2 gives the TG/DTG curves for the reduction of pyrolusite by the mixture of cellulose and lignin. The weight loss behaviors of the overall reduction processes of pyrolusite by the mixture of cellulose and hemicelluloses are also subdivided into three stages, which are similar to that in Fig.1. The main weight loss for the overall reduction of pyrolusite is also concentrated at the second stage.
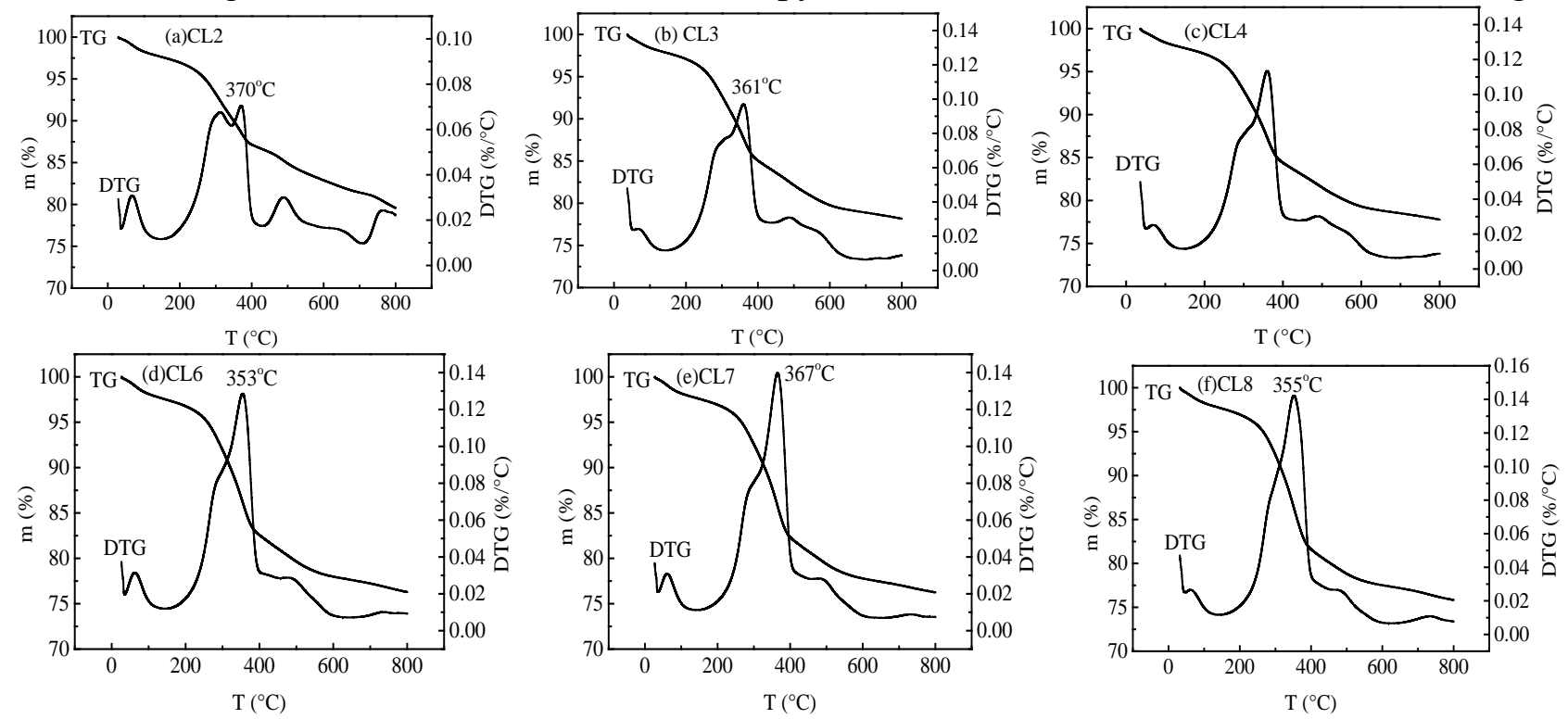

Fig. 2 TG-DTG curves of the reduction of pyrolusite by the mixture of cellulose and lignin

As shown in DTG curves of the Fig. 2, the second stages of six samples are composed of the peak accompanied by a small peak, and the peak temperature of the main peak is more close to that of CP than that of LP. Thus, the respective reduction processes are partial overlapped in the overall 
reduction processes of pyrolusite by the mixture cellulose and lignin.

According to the reported results ${ }^{[14,16,18]}$, various reductive volatiles (such as aldehydes, furans, ketones, alcohol, etc.) were produced in the pyrolysis of biomass, which directly reduced $\mathrm{MnO}_{2}$ in ore to $\mathrm{MnO}$. The reduction processes of pyrolusite by biomass are complex, which involved many kinds of reductive volatiles with different molecular structure and nature. Zhang reported that reduction of low-grade manganese dioxide ore by wheat stalk obey the kinetic model $\left[1-(1-\alpha)^{1 / 3}\right]^{2}=k t / r^{2}{ }^{[19]}$. Bamboo ${ }^{[18-19]}$, sawdust ${ }^{[19]}$, wheat stalk ${ }^{[19]}$ and straw ${ }^{[19-20]}$ reduction of low-grade manganese dioxide ore can be described by- $\ln (1-\alpha)=k t$. So, biomass reduction of manganese dioxide ore under investigation cannot fully be described by the conventional kinetic model function $f(a)$ because of the complexity of the reaction ${ }^{[28]}$. In this case, it can be useful to find an empirical function containing the smallest possible number of constants, so that there is some flexibility sufficient to describe the real process as closely as possible.

The Johnson-Mehl-Avrami (JMA) equation, usually written in the following form:

$$
\alpha=1-\exp \left(-k t^{n}\right)
$$

Where $k$ and $n$ are constants with respect to time $(t)$, and $\alpha$ is the degree of conversion. JMA equation has been used to describe the transformation kinetics of many solid state processes under isothermal conditions. ${ }^{[29]}$ When the temperature increases at a constant rate $\left(T=T_{0}+\beta t\right)$ and $k$ can be expressed by Arrhenius equation, Eq. (1) can be rewritten as follows:

$$
\alpha=1-\exp \left[-k_{0} \exp \left(-E_{a} / R T\right)\left(\left(T-T_{0}\right) / \beta\right)^{n}\right] \text {. }
$$

Where $\beta$ is the heating rate $\left(\mathrm{K} \cdot \mathrm{min}^{-1}\right), R$ is gas constant $\left(8.314 \mathrm{~J} \cdot \mathrm{mol}^{-1} \cdot \mathrm{K}^{-1}\right), E_{a}$ is apparent activation energy $\left(\mathrm{kJ} \cdot \mathrm{mol}^{-1}\right), k_{0}$ is constant and $\mathrm{T}_{0}$ is the initial temperature for the reaction $(\mathrm{K})$ determined from the DTG data. Hence, Eq. (2) is an empirical model based on JMA equation.

As indicated by the results of TG/DTG in Fig.1, the reduction processes of pyrolusite by cellulose and hemicelluloses are concentrated at the second stage. The degree of conversion $(\alpha)$ for the reduction of pyrolusite can be calculated from the TG/DTG data according to the formula:

$$
\alpha=\left(m_{0}-m_{T}\right) /\left(m_{0}-m_{F}\right) .
$$

Where $m_{0}$ and $m_{\mathrm{F}}$ are the weight of initial and end stage of the reaction, and $m_{\mathrm{T}}$ is the weight of the reaction at the temperature T. The degree of conversion $(\alpha)$ for the reduction of pyrolusite by cellulose and hemicelluloses was calculated and given in Fig. 3.
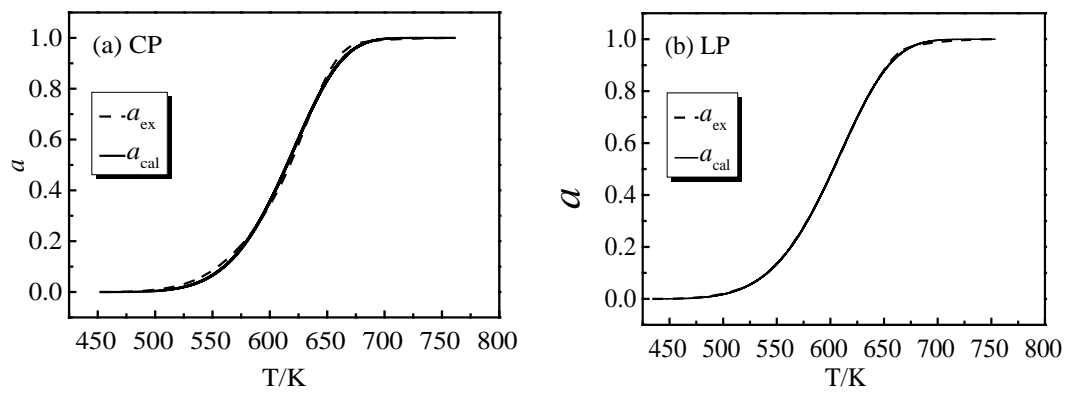

Fig.3 Respective kinetic analysis for CP (a) and LP (b)

The most appropriate parameters, $k_{0}, E_{a}$, and $n$, of the respective reduction are calculated simultaneously by the nonlinear least square analysis to be minimizing the square sum of the residue when fitting the experimental curve of $\alpha_{\exp }$ versus temperature by the calculated curve of $\alpha_{\text {cal }}$ versus temperature. The fitting results are presented in Table 2.

Table 2 Fitting results for cellulose and hemicelluloses reduction of pyrolusite

\begin{tabular}{cccccc}
\hline System & $k_{0}$ & $E_{a}\left(\mathrm{~kJ} \cdot \mathrm{mol}^{-1}\right)$ & $n$ & $T_{0}$ & $R^{2}$ \\
\hline CP & 3.75 & 38.66 & 2.81 & 452.66 & 0.997 \\
LP & 15.68 & 38.91 & 2.19 & 434.91 & 0.999 \\
\hline
\end{tabular}


As seen in Fig. 3 and Table 2, the calculated conversion data agree well with the experimental data, and the correlation coefficients $\left(R^{2}\right)$ for two reduction processes are greater than 0.99, indicating that these reduction processes can be described by Eq. (2). The apparent activation energy of cellulose reduction of pyrolusite and hemicelluloses reduction of pyrolusite is 38.66 $\mathrm{kJ} \cdot \mathrm{mol}^{-1}$ and $38.91 \mathrm{~kJ} \cdot \mathrm{mol}^{-1}$, respectively.

As long as the overall processes of the cellulose-hemicellulose mixture reduction of pyrolusite are composed of two independent kinetic processes, the overall kinetic behavior is expressed by the summation of the respective kinetic processes $i$ by considering their mass-loss fractions, $x_{i}$.

$$
\alpha=\sum_{i} x_{i} \alpha_{i} \quad \text { with } \sum_{i} x_{i}=1 .
$$

As seen in Table 3, initial temperatures $\mathrm{T}_{0}$ of CL2 is smaller that of CP, meaning that there are invalid conversion data calculated by Eq. (2). This problem can avoid by using a unit step function as following form.

$$
\alpha \varepsilon\left(T-T_{0}\right)=\left\{\begin{array}{ll}
0, & T-T_{0} \leq 0 \\
\alpha, & T-T_{0}>0
\end{array} .\right.
$$

The following overall kinetic equation can be obtained by combining Eqs. (2), (4) and (5):

$$
\begin{aligned}
& \alpha=x_{1}\left\{1-\exp \left[-3.75 \exp (-38660 / R T)((T-452.66) / \beta)^{2.81}\right]\right\} \varepsilon(T-452.66) \\
& +x_{2}\left\{1-\exp \left[-15.68 \exp (-38910 / R T)((T-434.91) / \beta)^{2.19}\right]\right\} \varepsilon(T-434.91)
\end{aligned}
$$

with $x_{1}+x_{2}=1$
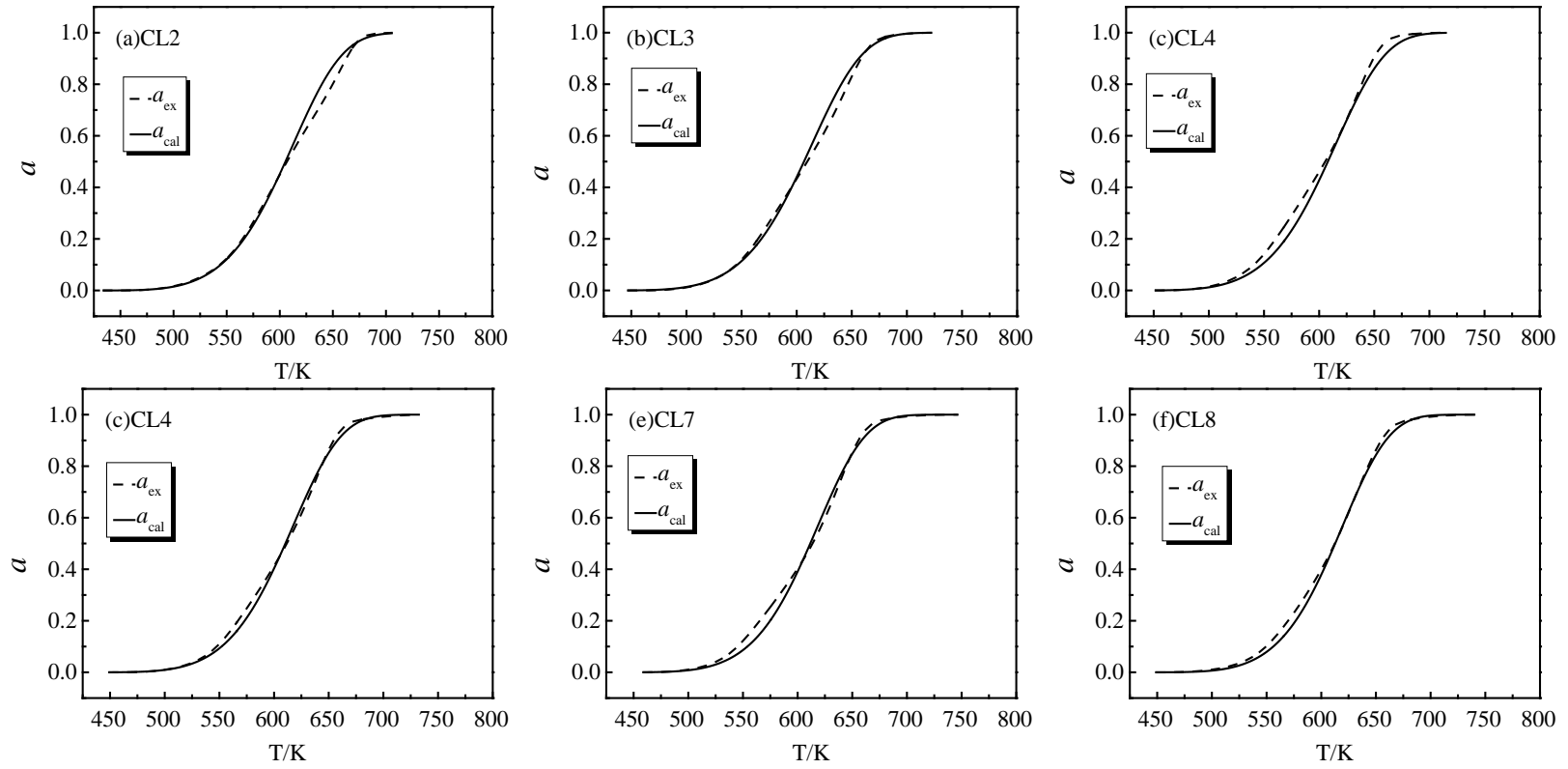

Fig.4. Kinetic analysis for the reduction of pyrolusite by mixture of cellulose and lignin

The experimental conversion data $\left(\alpha_{\exp }\right)$ for the cellulose-lignin mixture reduction of pyrolusite were calculated using Eq. (3) from the TG/DTG data in Fig. 4. The calculated conversion data $\left(\alpha_{\text {cal }}\right)$ in the temperature range of the cellulose-hemicellulose mixture reduction of pyrolusite are calculated using Eq. (6). $\alpha_{\text {exp }}$ and $\alpha_{\text {cal }}$ are given in Fig. 4. The following equation (Eq. (7)) was used to determine the adaptability of Eq. (6), and corresponding results are given in Table 3.

$$
\alpha_{\text {cal }}=B \cdot \alpha_{\text {exp }} \quad \text { where } Q=\sum_{i=1}^{N}\left(\alpha_{\text {cal }, i}-\alpha_{\text {exp }, i}\right)^{2}
$$

If the value of $B$ in Eq. (7) is 1, the calculated data are the same as the experimental values. 
As shown in Fig.4, the calculated data approximately agree with the experimental data. From Table 3, it can be seen that values of $B$ for six samples are close to 1 , and the correlation coefficients $\left(R^{2}\right)$ for these reduction processes are greater than 0.99 , indicating that the reduction of pyrolusite by the mixture of cellulose and hemicellulose can be simulated by Eq. (6).

Table 3 Results of adaptability analysis of Eq. (6)

\begin{tabular}{ccccccccc}
\hline & CP & CL2 & CL3 & CL4 & CL6 & CL7 & CL8 & LP \\
\hline$T_{0}$ & 452.66 & 447.42 & 460.52 & 454.08 & 459.21 & 458.79 & 454.18 & 434.91 \\
$a$ & 0.998 & 1.02 & 1.01 & 0.988 & 0.990 & 0.989 & 0.992 & 1.002 \\
$R^{2}$ & 0.999 & 0.998 & 0.998 & 0.998 & 0.999 & 0.998 & 0.999 & 0.999 \\
$Q$ & 0.294 & 0.775 & 0.658 & 0.771 & 0.415 & 0.845 & 0.430 & 0.020 \\
\hline
\end{tabular}

\section{Conclusion}

The overall kinetics of reduction processes of pyrolusite by the mixture of cellulose and lignin, two major components of biomass, were investigated. The TG/DTG results reveal that the weight loss behaviors of the reduction processes are subdivided into three stages, and the main reduction processes are the second stage. An empirical equation $\alpha=1-\exp \left[-k_{0} \exp \left(-E_{a} / R T\right)\left(\left(T-T_{0}\right) / \beta\right)^{n}\right]$ can be used describe the respective reduction of pyrolusite by cellulose and lignin, respectively. The apparent activation energy is $38.66 \mathrm{~kJ} \cdot \mathrm{mol}^{-1}$ and $38.91 \mathrm{~kJ} \cdot \mathrm{mol}^{-1}$ for the reduction of pyrolusite by cellulose and hemicellulose, respectively. The overall reduction processes of pyrolusite reduced by the mixture of cellulose and lignin are the partial overlapped processes of the respective reduction processes. The overall reduction kinetics can be simulated by the summation of the respective kinetic by considering their mass-loss fractions $\alpha=\sum_{i} x_{i} \alpha_{i} \varepsilon\left(T-T_{0, i}\right)$ with $\sum_{i} x_{i}=1$, where $\varepsilon\left(T-T_{0}\right)$ is the unit step function which was used to avoid conversion data.

\section{Acknowledgement}

In this paper, the research was sponsored by the National Natural Science Foundation of China (21166003) and the Doctoral Foundation of Ministry of Education of China (20114501110004).

\section{References}

[1] W. Zhang and C.Y. Cheng: Hydrometallurgy Vol. 89(2007), p.137

[2] I. De Michelis, F. Ferella, F. Beolchini and F. Vegliò: Waste. Manag. Vol. 29(2009), p.128

[3] P.K. Sahoo and K.S. Rao: J. Miner. Process Vol. 25(1989), p. 147

[4] C. Acharya and R.N. Kar: Miner. Eng.Vol. 16(2003), p. 1027

[5] C. Abbruzzese: Hydrometallurgy Vol. 25(1990), p. 85

[6] A.A. Ismail, E.A. Ali, I.A. Ibrahim and M.S. Ahmed: Can. J. Chem. Eng. Vol. 82(2004), p. 1296

[7] T. Jiang, Y. Yang, Z. Huang and G. Qiu: Hydrometallurgy Vol. 69(2003), p. 177

[8] Z. Cheng, G. Zhu and Y. N. Zhao: Hydrometallurgy Vol. 96(2009), p. 176-179

[9] Y.F. Long, J. Su, X.J. Ye, H.F. Su and Y. X. Wen: Adv. Mater. Res. Vol. 699(2013), p. 28

[10] J.J. Song, G. Zhu, P. Zhang and Y. Zhao: Acta Metall. Sin. (Engl. Lett.) Vol. 23(2010), p. 223

[11] K.D. Yang, X.J. Ye, J. Su, H.F. Su, Y.F. Long, X.Y. Lv and Y.X. Wen: Trans. Nonferrous Met. Soc. China Vol. 23(2013), p. 548 
[12] H. L. Zhang, G. Zhu, H. Yan, Y. Zhao, F. Chen and W. Wang: Acta Metall. Sin. (Engl. Lett.) Vol. 25(2012), p. 435

[13] H. Zhang, G. Zhu, H. Yan, Y. Zhao, T. Li and X. Feng: Acta Metall. Sin. (Engl. Lett.) Vol. 26(2013), p. 167

[14] Y.H. Zhou, H. Yao, Y.F. Long, J. Su, J. Liu, X.H. Zhou, T. Gang, Z.M. Lei and Y.X. Wen: Chin. J. Process Eng. Vol. 13(2013), p. 946

[15] M. Zhang, Y.C. Yuan and Y.Z. Liu: Energy Res. Inform. Vol. 21(2005), p. 1615

[16] X.J. Ye, J. Su, H.F. Su, Y.F. Long and Y.X. Wen: J. Guangxi Uni.: Nat. Sci. Ed.Vol. 37(2012), p. 440

[17]A.W. Coats and J.P. Redfern: Nature Vol. 201(1964), p. 68.

[18]T.C. Li and Y.N. Zhao: Metall. Mater. Trans. B Vol. 44B (2013), p. 889

[19] H. Zhang, G. Zhu, H. Yan, T. Li and X. Feng: Mater. Trans. B Vol. 44B (2013), p. 878

[20] Y.N. Zhao, G. Zhu and C. Zhuo: Hydrometallurgy Vol. 105(2010), p. 96

[21]T. Qu, W. Guo, L. Shen, J. Xiao and K. Zhao: Ind. Eng. Chem. Res. Vol. 50(2011), p. 10424

[22]S.V. Vassilev, D. Baxter, L. K. Andersen, C. G. Vassileva and T. J. Morgan: Fuel Vol. 94 (2012), p. 1

[24L. Burhenne, J. Messmer, T. Aicher and M. P. Laborie: J. Aanl. Appl. Pyrol. Vol. 101(2013), p. 177

[24] A. Corma, S. Iborra, and A. Velty: Chem. Rev.Vol. 107(2007), p. 2411

[25]C. DiBlasi, C. Branca and A. Galgano: Ind. Eng. Chem. Res.Vol. 49(2010), p. 2658

[26]S. Xin, H. Yang, Y. Chen, X. Wang and H. Chen: Fuel, 2013 Vol. 113(2013), p. 266

[27] H. Yang, R. Yan, H. Chen, D. H. Lee and C. Zheng: Fuel Vol. 86(2007), p. 1781

[28] N. Koga and J. Malek: Thermochim. Acta Vol. 282/283(19961), p. 69

[29] A. Khawam and D. R. Flanagan: J. Phys. Chem. B Vol. 110(2006), p. 17315 